Research Article

\title{
Simultaneous Determination of 5 Components in the Leaves of Dimocarpus longan by Quantitative Analysis of Multicomponents by Single Marker (QAMS) Based on UPLC and HPLC
}

\author{
Jiani Mai $\mathbb{D}^{1},{ }^{1}$ Jie Liang $\mathbb{D},{ }^{1,2,3}$ XianFu Liu, ${ }^{4}$ LiuPing Tan $\mathbb{D}^{1},{ }^{1}$ Hui Xu, ${ }^{1}$ YaoHua Li, ${ }^{1}$ \\ YuShan Zhou, ${ }^{1}$ ChuanChuan Yang, ${ }^{1}$ and ChenXi Xin ${ }^{1}$ \\ ${ }^{1}$ College of Pharmacy, Guangxi University of Chinese Medicine, Nanning 530222, Guangxi, China \\ ${ }^{2}$ GuangXi Key Laboratory of Zhuang and Yao Ethnic Medicine, Nanning 530200, China \\ ${ }^{3}$ Guangxi Zhuang Yao Medicine Center of Engineering and Technology, Nanning 530200, China \\ ${ }^{4}$ Faculty of Chinese Medicine Science, Guangxi University of Chinese Medicine, Nanning 530222, Guangxi, China
}

Correspondence should be addressed to Jie Liang; liangjie1101@126.com

Received 9 April 2019; Revised 13 June 2019; Accepted 28 July 2019; Published 29 January 2020

Academic Editor: Hana Sklenarova

Copyright (c) 2020 Jiani Mai et al. This is an open access article distributed under the Creative Commons Attribution License, which permits unrestricted use, distribution, and reproduction in any medium, provided the original work is properly cited.

The pharmacodynamic effect of longan leaves was attributed to various components, especially the flavonoids. In this paper, a new strategy of quantitative analysis of multicomponents by a single marker (QAMS) method was first established to synchronously determine 5 components (ethyl gallate $\left(\mathrm{C}_{1}\right)$, astragalin $\left(\mathrm{C}_{2}\right)$, quercetin $\left(\mathrm{C}_{3}\right)$, luteolin $\left(\mathrm{C}_{4}\right)$, and kaempferol $\left(\mathrm{C}_{5}\right)$ ) in Dimocarpus longan by ultraperformance liquid chromatography (UPLC) and high-performance liquid chromatography (HPLC). Quercetin ( $\left.\mathrm{C}_{3}\right)$ was chosen as the internal reference. Relative correction factors $\left(\mathrm{RCF}_{\mathrm{s}}, f_{\mathrm{s} / \mathrm{i}}\right)$ of the other 4 components were calculated by two correction methods (multipoint correction and slope correction) to effectuate QAMS. At the same time, the difference between the results measured by the QAMS and external standard methods was compared to verify the accuracy of QAMS. Within the linear range, the results showed that all $f_{\mathrm{s} / \mathrm{i}}$ values were obtained with good durability under diverse chromatographic conditions ( $\mathrm{RSD}<2.28 \%$ ). The quantitative results of 5 components in the leaves of Dimocarpus longan collected from 10 producing areas by different chromatographic systems and quantitative methods were significantly correlated (Pearson's $r>97.0 \%$ ). The applicability and feasibility of the QAMS method established in this study were evaluated to be favorable for quality control of the leaves of Dimocarpus longan. As a new model of quality control, it can provide one more choice of multicomponent quality-control method in the absence of standard substances or instruments.

\section{Introduction}

Quantitative analysis of multicomponents by a single marker (QAMS) is a new mode of multi-index evaluation. Using the relative correction factors between internal reference and other components, it only has to determine the internal reference in order to synchronously monitor the rest of the components [1-3]. Currently, the QAMS method has been used successfully in the quality control of various natural plant medicines in many countries [4]. For example, it has been collected in the China Pharmacopoeia (the 2015 Edition) to evaluate the quality of Coptis chinensis [5].
Trifolium pratense, Hypericum perforatum, Ranunculus ternatus, and Rubus idaeus extracts were recorded in the United States Pharmacopoeia (the 37 version). Echinacea pallida in the European Pharmacopoeia (EP 8.0) adopted QAMS [6-8].

Longan (Dimocarpus longan Lour.) is widely grown in Southern China especially in Guangxi, Guangdong, and Fujian provinces. In the antique book "Herbal Medicines of Southern Yunnan," there was recordation about the leaf of Dimocarpus longan Lour having effective Chinese herbal medicine which can be used to treat cold, fever, malaria, malignant sore, and eczema [9]. 
The effect of different polar extracts from Dimocarpus longan leaves on regulating blood glucose in type 2 diabetic mice in different extent were published in our group $[10,11]$. By Grey relational analysis and Pearson correlation analysis, it was found that the chromatographic peaks from Dimocarpus longan leaves were closely related to antioxidation and the activity of inhibiting $\alpha$-glucosidase enriched in ethyl acetate extracts. At present, the main chemical constituents ethyl gallate $\left(\mathrm{C}_{1}\right)$, astragalin $\left(\mathrm{C}_{2}\right)$, quercetin $\left(\mathrm{C}_{3}\right)$, luteolin $\left(\mathrm{C}_{4}\right)$, and kaempferol $\left(\mathrm{C}_{5}\right)$ have been found and separated from the leaves of Dimocarpus longan [12]. Studies have shown that $\mathrm{C}_{1}, \mathrm{C}_{2}, \mathrm{C}_{3}, \mathrm{C}_{4}$, and $\mathrm{C}_{5}$ in the leaves of Dimocarpus longan are the main components that exert pharmacological activity [13]. Therefore, it is meaningful to establish a quality standard that can rapidly and simultaneously evaluate the amount of these five components.

In our work, a new strategy of quantitative analysis of multicomponents by a single marker (QAMS) method for simultaneous quantification of 5 components in Dimocarpus longan by UPLC and HPLC was developed. Quercetin $\left(\mathrm{C}_{3}\right)$ as an internal reference for its stable property, low price, and easily acquiring standard substance was used to calculate RCFs of the other 4 components. The QAMS method was first established to control the quality of Dimocarpus longan leaves more conveniently, comprehensively, and synthetically, meanwhile investigating the feasibility of UPLC and HPLC methods based on chromatographic condition transformation.

\section{Materials and Methods}

2.1. Chemicals and Reagents. Reference standard of $\mathrm{C}_{3}$ was purchased from National Institutes for Food and Drug Control (China). The other four standards of reference substance were obtained from Shanghai Winherb Medical Science Co., Ltd. (Shanghai, China). The purity of all standards was verified to be more than $99 \%$ and had laboratory accreditation certificate. The structures of 5 marker constituents are listed in Figure 1. Methanol (Dikma technology Co., Ltd., HPLCgrade) and ultrapure water purified with Millipore Simplicity. All other chemicals were AR grade.

2.2. Plant Materials. Leaves of Dimocarpus longan Lour. used in the experiment were collected from 10 regions in Guangxi province in China and authenticated by associate professor Jian-bei Teng from the Guangxi University of Traditional Chinese Medicine.

2.3. Instrument and Chromatographic Conditions. In the initial study, four solvents including methanol, ethanol, mixed solvent 1 (methanol: hydrochloric acid), and mixed solvent 2 (ethanol: hydrochloric acid) were adopted to extract the medicinal materials, and gradient elution procedures of four mobile phase systems including acetonitrile: $0.2 \%$ phosphoric acid, acetonitrile: water, methanol: water, and methanol: $0.2 \%$ phosphoric acid were also compared to help acquiring a more optimized approach. The results showed that mixed solvent 2 was the best solvent for extraction, and when methanol: $0.2 \%$ phosphoric acid was used as mobile-phase gradient eluent, the separation effect of each chromatographic peak tested was the best.

The wavelength scanning of the sample set from $200 \mathrm{~nm}$ to $400 \mathrm{~nm}$ (Figure 2) showed that the maximum absorption wavelength of $\mathrm{C}_{1}$ was at about $280 \mathrm{~nm}$, while the rest of the components were strongly absorbed at $360 \mathrm{~nm}$. Therefore, the detection wavelength was changed after the peak of $\mathrm{C}_{1}$ in this study.

Analyses were performed on Agilent 1290 Infinity II and Agilent 1100 chromatographic systems equipped with a column temperature controller and VWD detector (Agilent, USA), respectively. The chromatographic separation was carried out on the reverse-phrase $\mathrm{C}_{18}$ columns including Thermo Syncronis $\mathrm{C}_{18}$ column (2.1ludi.mm, $\left.1.7 \mu \mathrm{m}\right)$ and Waters ACQUITY UPLC HSS $\mathrm{C}_{18}$ column (2.1rs A.mm, $1.8 \mu \mathrm{m})$. In the UPLC system, sample injection volume was $0.5 \mu \mathrm{L}$. The mobile phase comprising methanol (A) and $0.2 \%$ phosphoric acid (B) was programmed with gradient elution (0-3 $\mathrm{min}, 20 \%$ to $30 \% \mathrm{~A} ; 3-5 \mathrm{~min}, 30 \%$ to $38 \% \mathrm{~A} ; 5-20 \mathrm{~min}$, $38 \%$ to $75 \% \mathrm{~A})$ at a flow rate of $0.2 \mathrm{~mL} / \mathrm{min}$. The column temperature was maintained at $30^{\circ} \mathrm{C}$ and detection wavelength was set at $280 \mathrm{~nm}$ and then changed to $360 \mathrm{~nm}$ after $10 \mathrm{~min}$. According to the transformation formulas (1)-(3) $[14,15]$ and combining the actual situation after fine-tuning, the chromatographic conditions in HPLC determination can be intended as follows: Thermo Syncronis $\mathrm{C}_{18}$ column $(2.1 \mathrm{ermo} \cdot \mathrm{mm}, 1.7 \mu \mathrm{m})$ and Waters ACQUITY UPLC HSS $\mathrm{C}_{18}$ column (2.1rs A mm, $1.8 \mu \mathrm{m}$ ) were used for separation. Sample injection volume was $5.0 \mu \mathrm{L}$. The mobile phase was set with gradient elution (0-7 $\mathrm{min}, 20 \%$ to $30 \% \mathrm{~A} ; 7-12 \mathrm{~min}, 30 \%$ to $38 \% \mathrm{~A} ; 12-48 \mathrm{~min}, 38 \%$ to $75 \% \mathrm{~A}$ ) at a flow rate of $1.0 \mathrm{~mL} /$ min. The column temperature was at $30^{\circ} \mathrm{C}$ and detection wavelength was set at $280 \mathrm{~nm}$ and then converted to $360 \mathrm{~nm}$ after $22 \mathrm{~min}$.

$$
\begin{aligned}
v_{\text {target }} & =\frac{v_{\text {original }} \cdot d_{\text {target }}^{2}}{d_{\text {original }}^{2}}, \\
V_{\text {target injection }} & =\frac{V_{\text {original injection }} \cdot V_{\text {target injection }}}{V_{\text {original column }}}, \\
t_{\text {target }} & =\frac{t_{\text {original }} \cdot v_{\text {original }} \cdot V_{\text {target column }}}{V_{\text {original column }} \cdot v_{\text {original }}},
\end{aligned}
$$

where $v$ is the flow rate, $V$ is the volume, $d$ is the column inner diameter, and $t$ represents the gradient time.

2.4. Preparation of Standard Solutions. The applicable amounts of $\mathrm{C}_{1}, \mathrm{C}_{2}, \mathrm{C}_{3}, \mathrm{C}_{4}$, and $\mathrm{C}_{5}$ were accurately weighed and then put into $5 \mathrm{~mL}$ volumetric flasks in methanol separately to make the stock solutions. The concentrations were as follows: $\mathrm{C}_{1}, 1.226 \mathrm{mg} / \mathrm{mL} ; \mathrm{C}_{2}, 0.270 \mathrm{mg} / \mathrm{mL} ; \mathrm{C}_{3}$, $4.160 \mathrm{mg} / \mathrm{mL} ; \mathrm{C}_{4}, 0.230 \mathrm{mg} / \mathrm{mL} ; \mathrm{C}_{5}, 0.722 \mathrm{mg} / \mathrm{mL}$.

Working solution of mixtures of five standards was prepared by diluting the stock solutions to the concentration which contained $245.2 \mu \mathrm{g} \mathrm{C}_{1}, 108.0 \mu \mathrm{g} \mathrm{C}_{2}, 416.0 \mu \mathrm{g} \mathrm{C}_{3}$, $46.0 \mu \mathrm{g} \mathrm{C}_{4}$, and $72.2 \mu \mathrm{g} \mathrm{C}_{5}$ per milliliter erewhile before 
<smiles>CCOC(=O)c1cc(O)c(O)c(O)c1</smiles>

(a)<smiles>O=c1c(O)c(-c2ccc(O)c(O)c2)oc2cc(O)cc(O)c12</smiles>

(c)<smiles>O=c1c(O[C@@H]2OC(O)[C@H](O)C(O)[C@H](O)[C@H]2O)c(-c2ccc(O)c(O)c2)oc2cc(O)cc(O)c12</smiles>

(b)<smiles>O=c1cc(-c2ccc(O)c(O)c2)oc2cc(O)cc(O)c12</smiles>

(d)<smiles>O=c1c(O)c(-c2ccc(O)cc2)oc2cc(O)cc(O)c12</smiles>

(e)

Figure 1: The structures of 5 marker constituents. (a) $\mathrm{C}_{1}$ : ethyl gallate. (b) $\mathrm{C}_{2}$ : astragalin. (c) $\mathrm{C}_{3}$ : quercetin. (d) $\mathrm{C}_{4}$ : luteolin. (e) $\mathrm{C}_{5}$ : kaempferol.

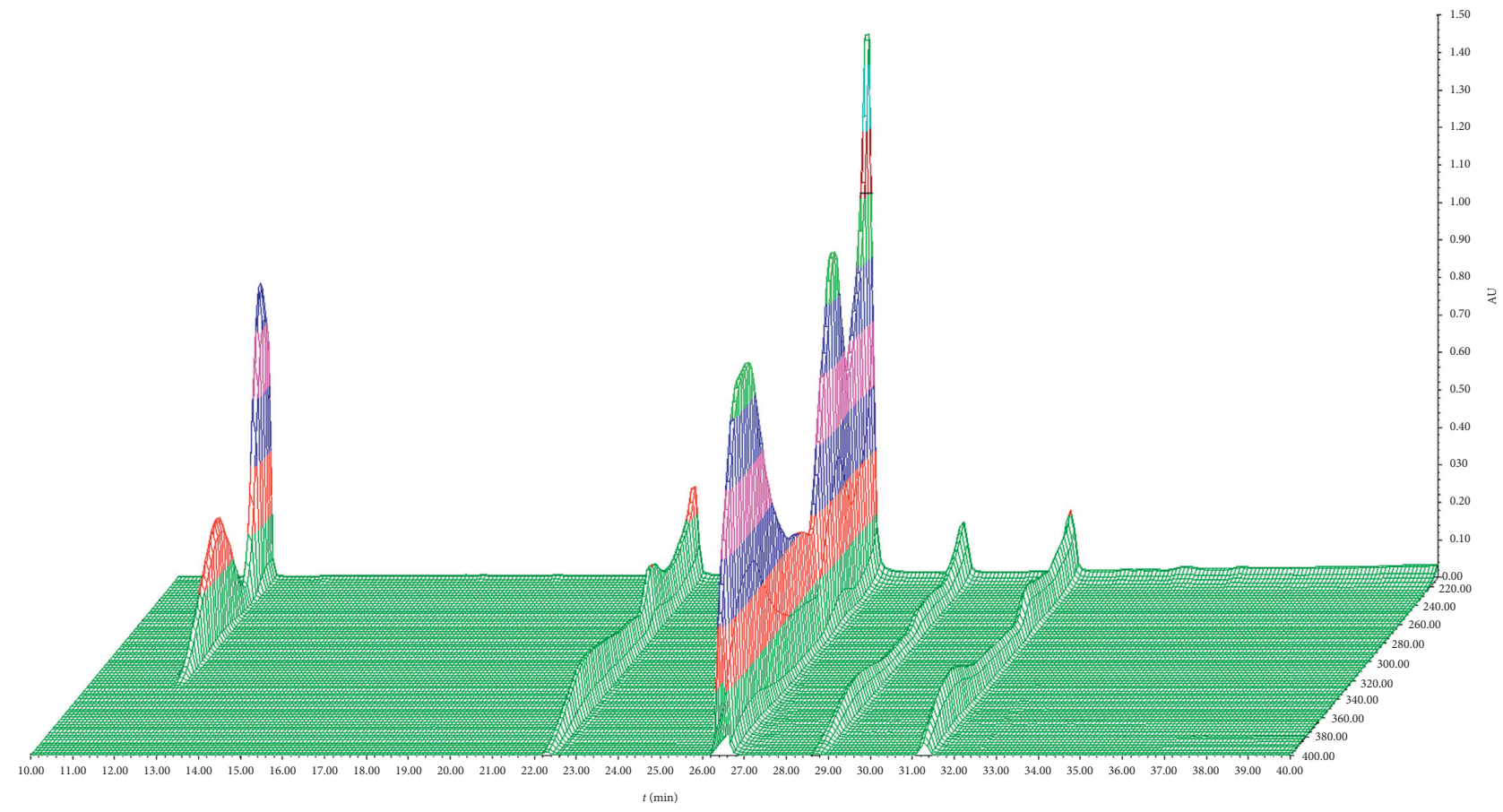

FIGURE 2: Full spectrum scan of five compounds. 
analyses. Stocking solutions and working solutions were kept in dark and stored at $4^{\circ} \mathrm{C}$.

2.5. Preparation of Sample Solutions. Approximately $4.0 \mathrm{~g}$ of Dimocarpus longan leaf powder was weighed and put into a dry Erlenmeyer flask with plug. The powder was blended with $20 \mathrm{~mL}$ of the extraction solvent (ethanol : hydrochloric acid, $9: 1, \mathrm{v} / \mathrm{v}$ ). The mixture was ultrasonicated at $80^{\circ} \mathrm{C}$ for $50 \mathrm{~min}$. After ultrasonication, extracts were replenished with the extraction solvent, then shaked, and centrifuged at a high speed. The supernatant was collected and stored at $4^{\circ} \mathrm{C}$. The sample solutions were filtered through $0.22 \mu \mathrm{m}$ membrane filters before injection.

\section{Results and Discussion}

3.1. Representative HPLC/UPLC Chromatograms. The chromatograms of mixed standard solutions and sample solutions were taken for analysis under the aforementioned corresponding conditions. The results testified that separation of the 5 components in Dimocarpus longan leaves with the peaks freed from interference by adjacent peaks was good. Resolution values of the 5 components were greater than 1.5 , and the chromatograms are shown in Figure 3.

\subsection{Method Validation}

3.2.1. Calibration Curves. Working solution of mixtures of five standards was injected into the UPLC and HPLC system separately in a series of volumes. Analysis was proceeded in accordance with the corresponding chromatographic conditions mentioned in Section 2.3. The peak area (A) was fitted linearly with the mass of substance $(\mu \mathrm{g})$ for establishing calibration curves. The results showed that the correlation coefficients of all standards were at least 0.9996 that presented good linear relations in the test range. The evaluation results are shown in Table 1.

3.2.2. Precision Test. The working solution of standards was injected 6 sequential times into the UPLC and HPLC systems, respectively, and the peak area of each component was recorded. In the UPLC system, the relative standard deviation ( $R S D$ ) values of peak area of $\mathrm{C}_{1}, \mathrm{C}_{2}, \mathrm{C}_{3}, \mathrm{C}_{4}$, and $\mathrm{C}_{5}$ were $0.38 \%, 0.17 \%, 0.18 \%, 0.34 \%$, and $0.23 \%$, respectively, while in the HPLC system, 0.69\%, 0.65\%, 0.92\%, 1.98\%, and $1.05 \%$, indicating that the precision of the instruments could be recognized precisely.

3.2.3. Stability Test. Stability was investigated by analyzing the sample solutions at $0,4,8,12,18$, and $24 \mathrm{~h}$ at room temperature and recording peak area of each component. The results in the UPLC system showed that the RSD value of peak area of $\mathrm{C}_{1}, \mathrm{C}_{2}, \mathrm{C}_{3}, \mathrm{C}_{4}$, and $\mathrm{C}_{5}$ was respectively $1.68 \%$, $1.52 \%, 0.39 \%, 0.73 \%$, and $1.06 \%$. It indicated that the sample solutions were stable within $24 \mathrm{~h}$.
3.2.4. Repeatability Test. The repeatability was determined by analyzing the 6 sample solutions dividually in the UPLC system, which were prepared in parallel according to the method in Section 2.5. The peak area of each component was recorded to calculate the RSD value. It was found that the RSD value of mass of $\mathrm{C}_{1}, \mathrm{C}_{2}, \mathrm{C}_{3}, \mathrm{C}_{4}$, and $\mathrm{C}_{5}$ was $0.21 \%, 0.85 \%, 0.51 \%, 1.02 \%$, and $0.93 \%$, respectively. The repeatability of the preparation method of sample solution was proved to be credible according to the results.

3.2.5. Sample Recovery Test. Recovery tests were performed to verify the accuracy of the method by adding the mixed standard solutions with known amount into the certain amount $(2.0 \mathrm{~g})$ of Dimocarpus longan leaf powder (9 portions). The mixtures of solutions and powders were extracted under the condition in Section 2.5 and analyzed by the UPLC system. The recoveries of the 5 components were in the range $93.28 \%-103.74 \%$, suggesting that the analysis methods were practicable.

\subsection{Determination of Relative Correction Factors}

3.3.1. Multipoint Correction. In the linear range, the detector response is directly proportional to the mass (or concentration) of the substance. By establishing the $\mathrm{RCF}_{\mathrm{s}}$ between the internal reference and the other components, the quantities of the components can be directly calculated in practical application $[16,17]$. In this study, $C_{3}$ was chosen as an internal reference. In linear range, the $\mathrm{RCF}_{\mathrm{s}}$ of $\mathrm{C}_{1}, \mathrm{C}_{2}, \mathrm{C}_{3}$, and $\mathrm{C}_{4}$ which was on different mass points were calculated according to formula (4), and the results are listed in Table 2. In general, if the components under test were similar in structure, the closer the maximum ultraviolet absorption wavelength they had, the closer to 1 the $f_{\mathrm{s} / i}$ value would be, the smaller the error would appear in practice, and the more feasible the application of QAMS method would be $[18,19]$.

$f_{\mathrm{s} / i}$ value of $\mathrm{C}_{3}, \mathrm{C}_{5}$, and $\mathrm{C}_{4}$ were all close to 1 since the only structural difference of them is the hydroxyl substitution position. Compared with $\mathrm{C}_{5}$, there is one more glucose group in $\mathrm{C}_{2}\left(f_{\mathrm{s} / i} \approx 0.5\right)$, which with less content in leaves of Dimocarpus longan turns out to be less than accurate relative in quantitative analysis by using the QAMS method. Besides, the relative inferior accuracy of peak location of $\mathrm{C}_{1}\left(f_{\mathrm{s} / i} \approx 0.4\right)$ may be related to the large difference with internal reference in structure.

$$
f_{\mathrm{s} / i}=\frac{f_{\mathrm{s}}}{f_{i}}=\frac{m_{\mathrm{s}} A_{i}}{m_{i} A_{\mathrm{s}}},
$$

where $m_{\mathrm{s}}$ is the mass of the internal standard, $A_{\mathrm{s}}$ is the peak area of internal standard, $m_{i}$ is the mass of the remaining components to be measured, and $A_{i}$ is the peak area of the remaining components to be measured.

3.3.2. Slope Correction Method. In he regression equation, the intercept is usually caused by system error. The slope correction method corrects the whole mean deviation caused by special point deviation in the multipoint correction method by means 


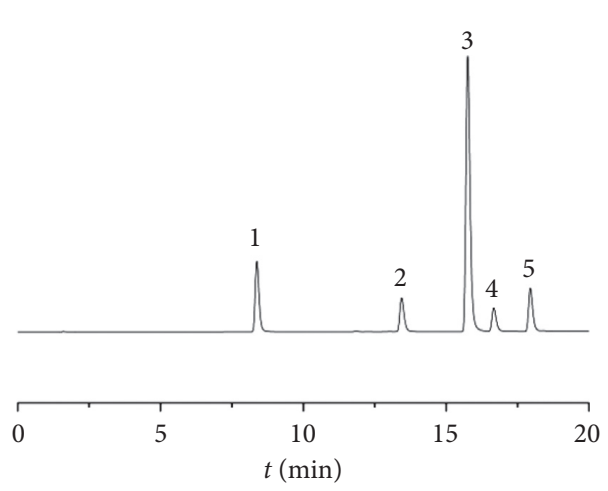

(a)

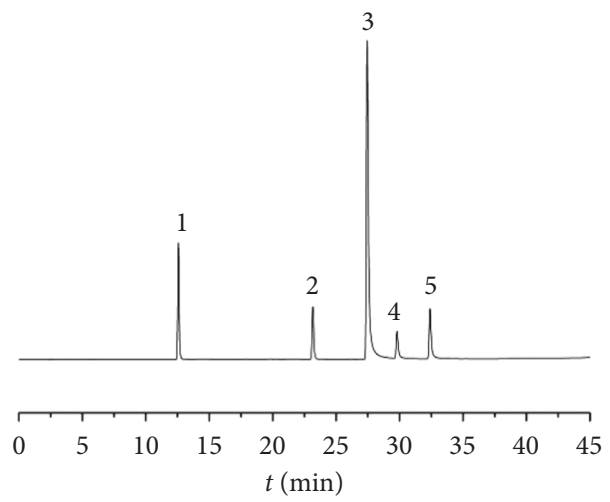

(c)

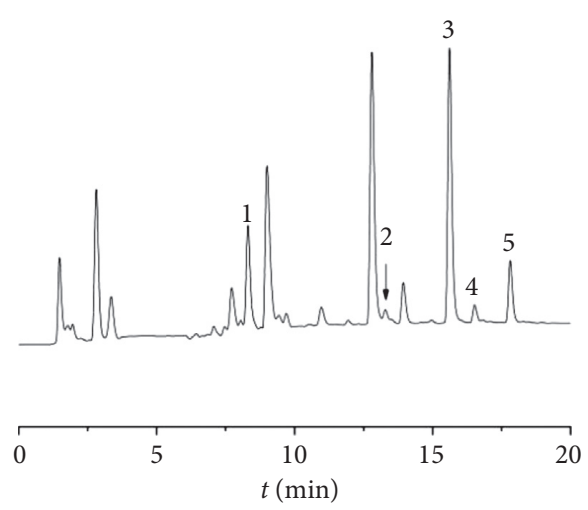

(b)

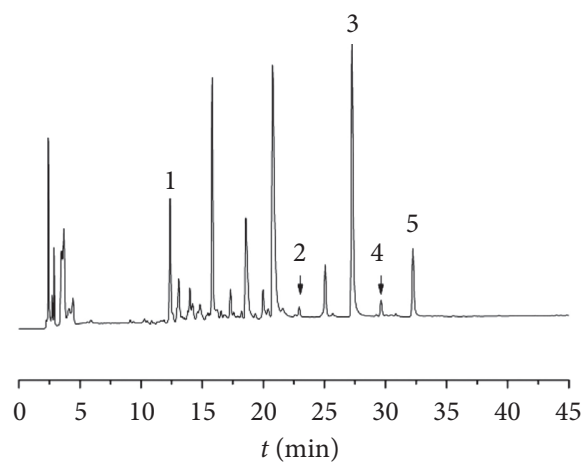

(d)

Figure 3: Chromatograms of the standard solutions and sample solutions. (1) Ethyl gallate. (2) Astragalin. (3) Quercetin. (4) Luteolin. (5) Kaempferol. (a) Mixed standard solution (UPLC); (b) sample solution (UPLC); (c) mixed standard solution (HPLC); (d) sample solution (HPLC).

TABLE 1: Results of linear relationships for the 5 components.

\begin{tabular}{lcccccc}
\hline \multirow{2}{*}{ Component } & & UPLC & & & \multicolumn{3}{c}{ HPLC } \\
& Calibration curve & $r$ & Linear range $(\mu \mathrm{g})$ & Calibration curve & $r$ & Linear range $(\mu \mathrm{g})$ \\
\hline $\mathrm{C}_{1}$ & $Y=7794.28 x-16.64$ & 0.99988 & $0.0490 \sim 0.245$ & $Y=1354.52 x+17.42$ & 0.99985 & $0.490 \sim 2.450$ \\
$\mathrm{C}_{2}$ & $Y=9618.87 x-13.22$ & 0.99972 & $0.0216 \sim 0.108$ & $Y=1713.83 x+4.38$ & 0.99981 & $0.216 \sim 1.080$ \\
$\mathrm{C}_{3}$ & $Y=19503.76 x-50.67$ & 0.99992 & $0.0832 \sim 0.416$ & $Y=3574.23 x+80.52$ & 0.99992 & $0.832 \sim 4.160$ \\
$\mathrm{C}_{4}$ & $Y=16010.58 x-7.42$ & 0.99983 & $0.00920 \sim 0.0460$ & $Y=2903.01 x-3.15$ & 0.99966 & $0.0920 \sim 0.460$ \\
$\mathrm{C}_{5}$ & $Y=17806.81 x-15.31$ & 0.99976 & $0.0144 \sim 0.0722$ & $Y=3249.11 x-16.06$ & 0.99964 & $0.144 \sim 0.722$ \\
\hline
\end{tabular}

of ignoring error. Based on it, $f_{\mathrm{s} / i}$ can be calculated directly in terms of the ratio of intercepts, that is, formula (5). Formula (6) derived from formula (5) can be used to quickly calculate the mass of each component [20]. The calculated results showed that within the linear range, $f_{\mathrm{C}_{3} / \mathrm{C}_{1}}=0.400, f_{\mathrm{C}_{3} / \mathrm{C}_{2}}=0.493$, $f_{\mathrm{C}_{3} / \mathrm{C}_{4}}=0.820$, and $f_{\mathrm{C}_{3} / \mathrm{C}_{5}}=0.913$ in the UPLC system; $f_{\mathrm{C}_{3} / \mathrm{C}_{1}}=0.379, f_{\mathrm{C}_{3} / \mathrm{C}_{2}}=0.479, f_{\mathrm{C}_{3} / \mathrm{C}_{4}}=0.812$, and $f_{\mathrm{C}_{3} / \mathrm{C}_{5}}=$ 0.909 in the HPLC system. The results of the slope correction method were similar to that of the multipoint correction method.

$$
\begin{aligned}
f_{\mathrm{s} / i} & =\frac{k_{i}}{k_{\mathrm{s}}}, \\
m_{i} & =\frac{A_{i}}{k_{\mathrm{s}} \cdot f_{\mathrm{s} / i}},
\end{aligned}
$$

where $k_{\mathrm{s}}$ is the slope of the internal standard and $k_{i}$ is the slope of other components.

\subsection{Durability Evaluation of RCFs}

3.4.1. Repeatability. To verify the repeatability of the RCFs, 6 sample solutions prepared in parallel from the same sample were analyzed. According to multipoint correction, the RSD value of $f_{\mathrm{C}_{3} / \mathrm{C}_{1}}, f_{\mathrm{C}_{3} / \mathrm{C}_{2}}, f_{\mathrm{C}_{3} / \mathrm{C}_{4}}$, and $f_{\mathrm{C}_{3} / \mathrm{C}_{5}}$ in the UPLC system was figured out to be $0.19 \%, 0.71 \%$, $0.22 \%$, and $0.47 \%$, respectively, while in the HPLC system, it was $0.27 \%, 0.30 \%, 1.77 \%$, and $0.42 \%$, respectively. Repeatability of RCFs turned out satisfactory based on the results above. 
TABLE 2: Correction $f_{\mathrm{s} / i}$ of 5 constituents.

\begin{tabular}{|c|c|c|c|c|c|}
\hline \multirow{2}{*}{ Chromatographic system } & \multirow{2}{*}{ Injection volume $(\mu \mathrm{L})$} & \multicolumn{4}{|c|}{$\mathrm{RCF}_{\mathrm{s}}$} \\
\hline & & $f_{\mathrm{C}_{3} / \mathrm{C}_{1}}$ & $f_{\mathrm{C}_{3} / \mathrm{C}_{1}}$ & $f_{\mathrm{C}_{3} / \mathrm{C}_{1}}$ & $f_{\mathrm{C}_{3} / \mathrm{C}_{1}}$ \\
\hline \multirow{6}{*}{ UPLC } & 0.2 & 0.395 & 0.477 & 0.805 & 0.886 \\
\hline & 0.4 & 0.397 & 0.485 & 0.813 & 0.900 \\
\hline & 0.5 & 0.398 & 0.487 & 0.815 & 0.903 \\
\hline & 0.6 & 0.398 & 0.490 & 0.816 & 0.907 \\
\hline & 0.8 & 0.398 & 0.489 & 0.814 & 0.906 \\
\hline & 1.0 & 0.399 & 0.490 & 0.818 & 0.908 \\
\hline Means & & 0.397 & 0.486 & 0.813 & 0.902 \\
\hline RSD (\%) & & 0.34 & 0.96 & 0.51 & 0.82 \\
\hline \multirow{6}{*}{ HPLC } & 2 & 0.379 & 0.472 & 0.781 & 0.894 \\
\hline & 4 & 0.379 & 0.476 & 0.797 & 0.882 \\
\hline & 5 & 0.379 & 0.477 & 0.800 & 0.887 \\
\hline & 6 & 0.379 & 0.477 & 0.802 & 0.891 \\
\hline & 8 & 0.379 & 0.478 & 0.804 & 0.895 \\
\hline & 10 & 0.379 & 0.478 & 0.806 & 0.898 \\
\hline Means & & 0.379 & 0.476 & 0.798 & 0.891 \\
\hline RSD (\%) & & 0.02 & 0.39 & 1.02 & 0.62 \\
\hline
\end{tabular}

TABle 3: Robustness test of $f_{\mathrm{s} / i}$.

\begin{tabular}{|c|c|c|c|c|c|}
\hline & \multirow{2}{*}{ Influencing factors } & \multicolumn{4}{|c|}{ RCFs } \\
\hline & & $f_{\mathrm{C}_{3} / \mathrm{C}_{1}}$ & $f_{\mathrm{C}_{3} / \mathrm{C}_{2}}$ & $f_{\mathrm{C}_{3} / \mathrm{C}_{4}}$ & $f_{\mathrm{C}_{3} / \mathrm{C}_{5}}$ \\
\hline \multirow{6}{*}{ UPLC } & Column: Waters & 0.397 & 0.479 & 0.817 & 0.902 \\
\hline & Column: Thermo & 0.398 & 0.479 & 0.824 & 0.901 \\
\hline & Flow rate: $0.2 \mathrm{ml} / \mathrm{min}$ & 0.397 & 0.481 & 0.812 & 0.897 \\
\hline & Flow rate: $0.3 \mathrm{ml} / \mathrm{min}$ & 0.391 & 0.479 & 0.803 & 0.889 \\
\hline & Column temperature: $25^{\circ} \mathrm{C}$ & 0.393 & 0.487 & 0.808 & 0.925 \\
\hline & Column temperature: $30^{\circ} \mathrm{C}$ & 0.396 & 0.481 & 0.809 & 0.895 \\
\hline \multirow{4}{*}{ HPLC } & Column temperature: $35^{\circ} \mathrm{C}$ & 0.399 & 0.482 & 0.818 & 0.901 \\
\hline & Column: Phenomenex & 0.376 & 0.471 & 0.785 & 0.879 \\
\hline & Column: Agilent & 0.377 & 0.471 & 0.775 & 0.893 \\
\hline & RSD (\%) & 2.28 & 1.06 & 2.07 & 1.48 \\
\hline
\end{tabular}

3.4.2. Robustness. In order to investigate the robustness of RCFs in different chromatographic conditions, including instruments, columns, flow rates, and column temperatures, the mixed standard solution was injected and analyzed. The results showed that the RCFs of each component were not significantly different $(\mathrm{RSD}<2.28 \%)$ under the above influencing factors, as shown in Table 3.

3.5. Identification of Chromatographic Peaks. The relative retention time of the components under test in different chromatographic systems was investigated so as to identify the chromatographic peaks of the components when $\mathrm{C}_{3}$ was only used as standard reference. The results shown in Table 4 indicate that relative retention time is accurate for peaks location and can be used as a parameter for identification of chromatographic peaks.

3.6. Comparison of the QAMS Method with External Standard Method. At present, the external standard method (ESM) has become one of the most effective methods in the fields of multicomponent quantitative and qualitative analysis [21]. To evaluate the feasibility of the QAMS method, leaves of Dimocarpus longan were collected from 10 regions in Guangxi province in China to prepare sample solutions. Two instruments (UPLC and HPLC instruments) were used for sample analysis. Then, the amount of each component in the sample was calculated by using ESM, multipoint correction method (QAMS1), and slope correction method (QAMS2), respectively. The results are shown in Tables 5 and 6 and Figure 4; it was found that the quantitative results of 5 components calculated by the external standard method had significant correlation in different instruments and Pearson's coefficient ( $\mathrm{r}$ ) was at least 0.970 . In addition, the results obtained by the QAMS method significantly correlated with the results of ESM, indicating that the different chromatographic systems and the method applied in this study were reasonable and feasible for the determination of the amounts of $\mathrm{C}_{1}, \mathrm{C}_{2}, \mathrm{C}_{3}, \mathrm{C}_{4}$, and $\mathrm{C}_{5}$ in Dimocarpus longan leaves. 
TABLE 4: Relative retention time of 5 constituents.

\begin{tabular}{|c|c|c|c|c|c|}
\hline \multirow{2}{*}{\multicolumn{2}{|c|}{ Chromatographic systems }} & \multicolumn{4}{|c|}{ Relative retention time } \\
\hline & & $R_{\mathrm{tC}_{1} / \mathrm{C}_{3}}$ & $R_{\mathrm{tC}_{2} / \mathrm{C}_{3}}$ & $R_{\mathrm{tC}_{4} / \mathrm{C}_{3}}$ & $R_{\mathrm{tC}_{5} / \mathrm{C}_{3}}$ \\
\hline \multirow{2}{*}{ UPLC } & Column: Waters & 0.541 & 0.828 & 1.062 & 1.179 \\
\hline & Column: Thermo & 0.542 & 0.828 & 1.062 & 1.179 \\
\hline \multirow{4}{*}{ HPLC } & Column: Phenomenex & 0.495 & 0.844 & 1.086 & 1.180 \\
\hline & Column: Agilent & 0.493 & 0.834 & 1.070 & 1.174 \\
\hline & Means & 0.518 & 0.833 & 1.070 & 1.178 \\
\hline & RSD (\%) & 5.33 & 0.93 & 1.04 & 0.22 \\
\hline
\end{tabular}

Table 5: Determination of 5 constituents using different instruments ( $\mathrm{mg} / \mathrm{g}, n=3)$.

\begin{tabular}{|c|c|c|c|c|c|c|c|c|c|c|}
\hline \multirow{2}{*}{ Regions } & \multicolumn{2}{|c|}{$\mathrm{C}_{1}$} & \multicolumn{2}{|c|}{$\mathrm{C}_{2}$} & \multicolumn{2}{|c|}{$\mathrm{C}_{3}$} & \multicolumn{2}{|c|}{$\mathrm{C}_{4}$} & \multicolumn{2}{|c|}{$\mathrm{C}_{5}$} \\
\hline & UPLC & HPLC & UPLC & HPLC & UPLC & HPLC & UPLC & HPLC & UPLC & HPLC \\
\hline Beihai & 1.918 & 1.940 & 0.356 & 0.346 & 1.073 & 0.955 & 0.144 & 0.146 & 0.225 & 0.229 \\
\hline Qinzhou & 2.679 & 2.796 & 0.341 & 0.363 & 2.438 & 2.425 & 0.157 & 0.161 & 0.561 & 0.639 \\
\hline Wuzhou & 1.828 & 1.824 & 0.237 & 0.225 & 1.842 & 1.835 & 0.148 & 0.150 & 0.460 & 0.469 \\
\hline Yulin & 1.631 & 1.698 & 0.261 & 0.264 & 1.799 & 1.799 & 0.140 & 0.148 & 0.425 & 0.421 \\
\hline Nanning & 2.587 & 2.617 & 0.289 & 0.276 & 1.601 & 1.613 & 0.172 & 0.167 & 0.471 & 0.469 \\
\hline Chongzuo & 1.850 & 1.827 & 0.266 & 0.243 & 0.426 & 0.443 & 0.109 & 0.115 & 0.213 & 0.210 \\
\hline Liuzhou & 1.259 & 1.234 & 0.303 & 0.309 & 3.521 & 3.372 & 0.145 & 0.143 & 0.892 & 0.931 \\
\hline Guigang & 1.880 & 1.882 & 0.220 & 0.216 & 2.589 & 2.410 & 0.189 & 0.194 & 0.751 & 0.798 \\
\hline Hezhou & 2.915 & 3.002 & 0.260 & 0.262 & 1.936 & 1.918 & 0.192 & 0.184 & 0.522 & 0.571 \\
\hline Fangchenggang & 1.462 & 1.490 & 0.286 & 0.280 & 0.699 & 0.685 & 0.129 & 0.128 & 0.358 & 0.392 \\
\hline Pearson's coefficient $(\mathrm{r})$ & \multicolumn{2}{|c|}{$0.998^{* *}$} & \multicolumn{2}{|c|}{$0.970^{* *}$} & \multicolumn{2}{|c|}{$0.998^{* *}$} & \multicolumn{2}{|c|}{$0.982^{* *}$} & \multicolumn{2}{|c|}{$0.995^{* *}$} \\
\hline
\end{tabular}

**At level 0.01 (two-tailed), the correlation was significant.

TABle 6: Determination of 5 constituents by different quantitative methods ( $\mathrm{mg} / \mathrm{g}, n=3$ ).

\begin{tabular}{|c|c|c|c|c|c|c|c|c|c|c|c|c|c|}
\hline \multirow{2}{*}{ Regions } & \multicolumn{3}{|c|}{$\mathrm{C}_{1}$} & \multicolumn{3}{|c|}{$\mathrm{C}_{2}$} & \multicolumn{3}{|c|}{$\mathrm{C}_{4}$} & \multicolumn{3}{|c|}{$\mathrm{C}_{5}$} & \multirow{2}{*}{$\begin{array}{c}\mathrm{C}_{3} \\
\mathrm{ESM}\end{array}$} \\
\hline & ESM & QAMS1 & QAMS2 & ESM & QAMS1 & QAMS2 & ESM & QAMS1 & QAMS2 & ESM & QAMS1 & QAMS2 & \\
\hline Beihai & 1.918 & 1.955 & 1.895 & 0.356 & 0.356 & 0.343 & 0.144 & 0.144 & 0.140 & 0.225 & 0.225 & 0.216 & 1.073 \\
\hline Qinzhou & 2.679 & 2.702 & 2.656 & 0.341 & 0.336 & 0.327 & 0.157 & 0.155 & 0.153 & 0.561 & 0.566 & 0.553 & 2.438 \\
\hline Wuzhou & 1.828 & 1.843 & 1.805 & 0.237 & 0.229 & 0.223 & 0.148 & 0.146 & 0.143 & 0.460 & 0.464 & 0.452 & 1.842 \\
\hline Yulin & 1.631 & 1.643 & 1.609 & 0.261 & 0.255 & 0.247 & 0.140 & 0.139 & 0.136 & 0.425 & 0.428 & 0.416 & 1.799 \\
\hline Nanning & 2.587 & 2.623 & 2.564 & 0.289 & 0.284 & 0.275 & 0.172 & 0.172 & 0.168 & 0.471 & 0.476 & 0.463 & 1.601 \\
\hline Chongzuo & 1.850 & 1.959 & 1.827 & 0.266 & 0.272 & 0.252 & 0.109 & 0.112 & 0.104 & 0.213 & 0.221 & 0.205 & 0.426 \\
\hline Liuzhou & 1.259 & 1.254 & 1.237 & 0.303 & 0.295 & 0.289 & 0.145 & 0.143 & 0.141 & 0.892 & 0.897 & 0.880 & 3.521 \\
\hline Guigang & 1.880 & 1.888 & 1.857 & 0.220 & 0.212 & 0.207 & 0.189 & 0.188 & 0.184 & 0.751 & 0.759 & 0.742 & 2.589 \\
\hline Hezhou & 2.915 & 2.950 & 2.891 & 0.260 & 0.253 & 0.247 & 0.192 & 0.192 & 0.188 & 0.522 & 0.527 & 0.514 & 1.936 \\
\hline Fangchenggang & 1.462 & 1.505 & 1.439 & 0.286 & 0.287 & 0.273 & 0.129 & 0.130 & 0.124 & 0.358 & 0.368 & 0.349 & 0.699 \\
\hline Pearson's coefficient $(r)$ & & $0.998^{* *}$ & $1.000^{* *}$ & & $0.995^{* *}$ & $1.000^{* *}$ & & $0.998^{* *}$ & $1.000^{* *}$ & & $1.000^{* *}$ & $1.000^{* *}$ & \\
\hline
\end{tabular}

**At level 0.01 (two-tailed), the correlation was significant.

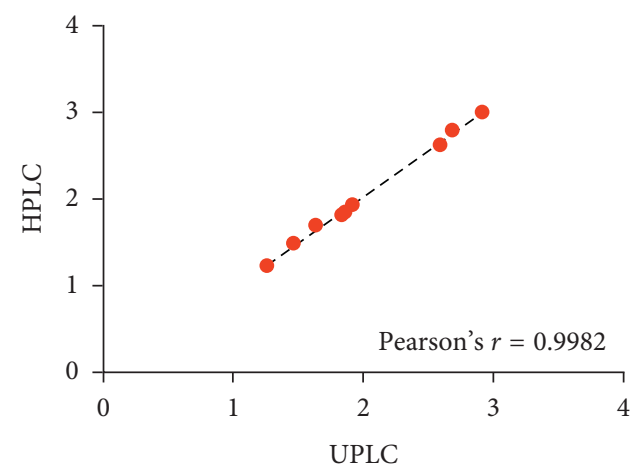

(a)

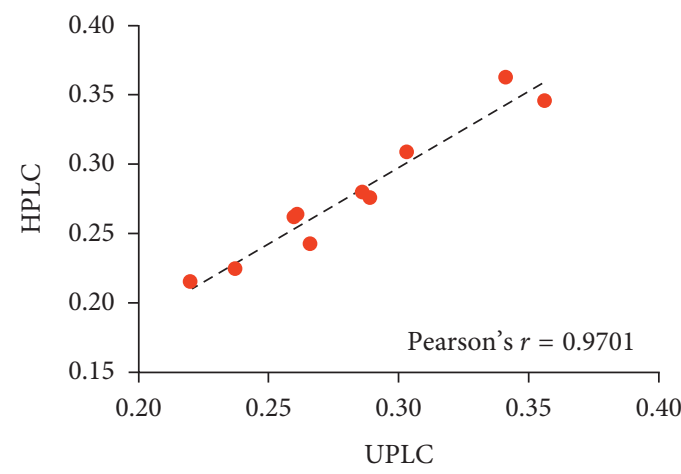

(b)

Figure 4: Continued. 


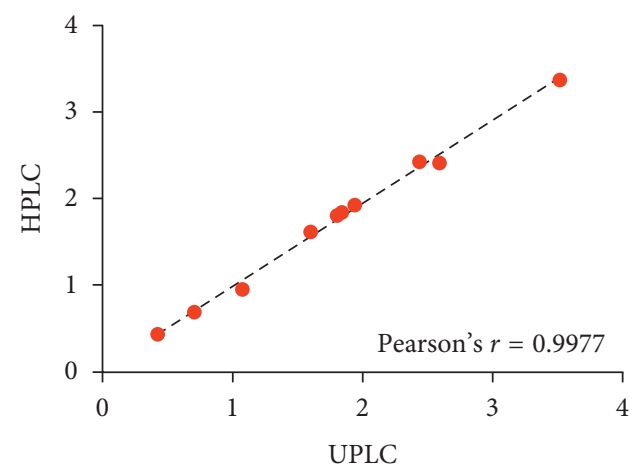

(c)

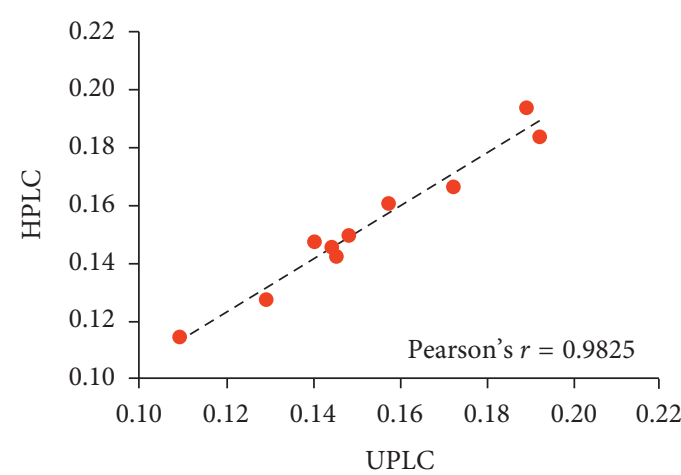

(d)

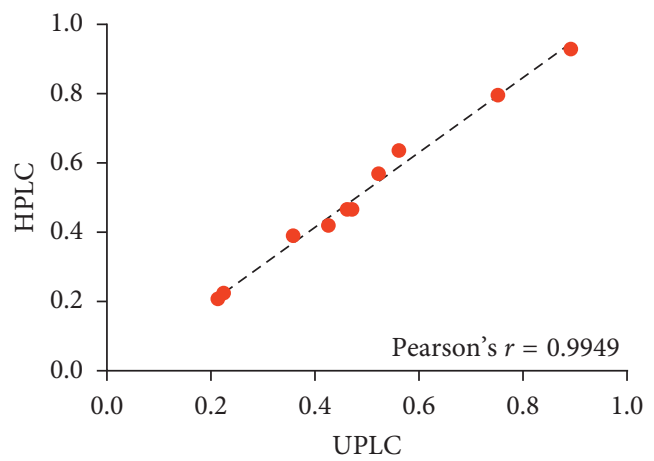

(e)

Figure 4: The similarity of detection results of different compounds by different chromatographic systems. (a) $\mathrm{C}_{1}$, (b) $\mathrm{C}_{2}$, (c) $\mathrm{C}_{3}$, (d) $\mathrm{C}_{4}$, and (e) $\mathrm{C}_{5}$.

\section{Conclusion}

The accurate identification of chromatographic peaks is a key part of the QAMS method. At present, relative retention time or retention time difference is commonly used to locate chromatographic peaks in most studies [22]. However, in most cases, positioning by the retention time difference is not effective and the data fluctuate severely [23]. Therefore, relative retention time is more widely used for peak positioning in the QAMS method. In this study, the relative retention time of the components was investigated in different chromatographic systems. The results showed that, in different chromatographic systems, the relative retention times of the components except $\mathrm{C}_{1}$ were all less than $1.04 \%$ with a negligible deviation, which could be used as the peak location parameters. But there are also studies that suggest the premise of applying relative retention time for positioning is to use chromatographic columns with the same filler and similar chromatographic behavior.

If the relative correction method is not effective, methods such as linear regression and trailing control can be adopted $[18,24,25]$, or a little amount of standard reference can be used to qualitatively and accurately locate the peaks, and then the mass fraction of components can be calculated by using the RCFs [26].

In order to verify the rationality and feasibility of the application of the QAMS method for quantitating the 5 components in the leaves of Dimocarpus longan, methodological investigations including system adaptability test and durability evaluation of RCFs were carried out under different chromatographic systems. The results with good reproducibility were acquired in different conditions such as chromatography systems, columns, flow rate, and column temperature.

This study verified the universality of RCFs evaluated by the QAMS method in different chromatographic systems. In addition, the QAMS method was applied for determination of the content of Dimocarpus longan leaves for the first time, which laid the foundation for establishment of multi-index quality control of Dimocarpus longan leaves and also provided an alternative method in the absence of standard reference or instruments.

\section{Data Availability}

The data used to support the findings of this study are available from the corresponding author upon request.

\section{Conflicts of Interest}

The authors declare that there are no conflicts of interest regarding the publication of this paper.

\section{Acknowledgments}

This project was financially supported by the National Natural Science Foundation of China (no. 81560691), Open Tasks Basis on the Construction Project of Doctoral Station 
of Traditional Chinese Pharmacology by the Guangxi University of Traditional Chinese Medicine (no. 201410-06), Collaborative Innovation Center of Zhuang \& Yao Medicine ([2013]20), Guangxi Province Key Laboratory of Zhuang \& Yao Medicine ([2014]32), High Level Innovation Team and Excellent Scholar Program of Guangxi Universities ([2019] 52), and the Project of Cultivating High-level Talent Teams in the "Qi Huang Project" of the Guangxi University of Chinese Medicine (2018002).

\section{References}

[1] Z. M. Wang, H. M. Gao, X. T. Fu, and W. H. Wang, "Multicomponents quantitation by one marker new method for quality evaluation of Chinese herbal medicine," China Journal of Chinese Material Medica, vol. 31, no. 23, pp. 1925-1928, 2006.

[2] L. L. Lu, D. W. Qian, J. M. Guo et al., “A quantitative method using one marker for simultaneous assay of seven flavonoids in the flowers of Abelmoschus manihot," Chinese Journal of Pharmaceutical Analysis, vol. 33, pp. 2082-2087, 2013.

[3] L. Cui, Y. Zhang, W. Shao, and D. Gao, "Analysis of the HPLC fingerprint and QAMS from Pyrrosia species," Industrial Crops and Products, vol. 85, pp. 29-37, 2016.

[4] G. Kuang, J. Zhou, M. Yao et al., "Systematic study on QAMS method for simultaneous determination of triterpenoid saponins in Ilex pubescens by HPLC and UPLC," Analytical Methods, vol. 7, no. 16, pp. 6579-6587, 2015.

[5] Chinese Pharmacopoeia, Part 2015.

[6] The United States Pharmacopeial Convention, The United States Pharmacopoeia 37-National Formulary 32, Vol. 4, United Book Press, Inc., Baltimore, ND, USA, 2014.

[7] D.-W. Li, M. Zhu, Y.-D. Shao, Z. Shen, C.-C. Weng, and W.-D. Yan, "Determination and quality evaluation of green tea extracts through qualitative and quantitative analysis of multi-components by single marker (QAMS)," Food Chemistry, vol. 197, pp. 1112-1120, 2016.

[8] The Directorate for the Quality of Medicines \& Health Care of the Council of Europe (EDQM), European Pharmacopoeia 8.0.

[9] Jiangsu New Medical College, Dictionary of Traditional Chinese Medicine, Vol. 1, Shanghai Science and Technology Press, Shanghai, China, 2nd edition, 2006.

[10] J. Liang, L. Yu, X. F. Liu, and Z. Y. Sun, "Experimental study on hypoglycemic effect of different extracts from longan leaves," Lishizhen Medicine and Materia Medica Research, vol. 24, pp. 2057-2058, 2013.

[11] J. Liang, Q. Q. Jin, T. X. Huang, X. Hu, J. N. Mai, and C. X. Xin, "Study on hypoglycemic effects of different polar parts from the leaves of dimocarpus longan on type 2 diabetes mellitus mice," Chinese Pharmacy, vol. 29, pp. 950-954, 2018.

[12] C. Y. Huang, J. Liang, J. N. Mai, H. Xu, and Q. Q. Jin, "Chemical constituents from the leaves of dimocarpus longan," Journal of Chinese Medicinal Materials, vol. 40, pp. 2344-2346, 2017.

[13] J. Liang, C. Y. Huang, J. N. Mai, H. Xu, C. C. Yang, and L. C. Zhao, "Study on $\alpha$-glucosidase inhibitory activity of chemical components and structure-activity relationship in the leaf of dimocarpus longan lour," Lishizhen Medicine and Materia Medica Research, vol. 29, pp. 2104-2107, 2018.

[14] Q. Gao, Y. Liu, B. B. Song, F. Long, W. Guo, and Z. Z. Qian, "Method conversion and validation between HPLC and UPLC," Chinese Journal of Pharmaceutical Analysis, vol. 36, pp. 1279-1286, 2016.
[15] Waters, HPLC to UPLC Method Migration: An Overview of Key Sourand Available Tools [Waters Technical Notes/Online resource][K/OL], 2015.

[16] X. Y. Chi, Y. X. Cui, S. Zhang, and H. Deng, "Quantitative analysis of 4 components in Isatidis Radix granules using single marker by QAMS," Chinese Journal of Biochemical and Pharmaceuticals, vol. 35, pp. 137-140, 2015.

[17] J. J. Zhu, Z. M. Wan, H. M. Gao et al., "Advances on quality evaluation of chinese materia medica by QAMS," Chinese Journal of Experimental Traditional Medical Formulae, vol. 22, pp. 220-228, 2016.

[18] J. J. Wang, L. Zhang, Q. Guo, J. P. Kou, B. Y. Yu, and D. H. Gu, "Quantitative analysis of seven phenolic acids in eight Yinqiao Jiedu serial preparations by quantitative analysis of multicomponents with single-marker," Acta Pharmaceutica Sinica, vol. 50, pp. 480-485, 2015.

[19] B. He, Y. Liu, S. Y. Yang, and Y. Zhang, "Simultaneous determination of 10 constituents in Shuangqing Yanhou Tablets by HPLC-QAMS," Chinese Traditional and Herbal Drugs, vol. 44, pp. 974-981, 2013.

[20] B. He, Y. Liu, S. Y. Yang, and Y. Zhang, "Determination of 10 active constituents in Farfarae Flos by quantitative analysis of multi-components by single marker," Chinese Journal of Pharmaceutical Analysis, vol. 33, pp. 1518-1524, 2013.

[21] J.-Q. Jin, J.-Q. Ma, C.-L. Ma, M.-Z. Yao, and L. Chen, "Determination of catechin content in representative Chinese tea germplasms," Journal of Agricultural and Food Chemistry, vol. 62, no. 39, pp. 9436-9441, 2014.

[22] L. Li, S. Zhao, J. N. Luo et al., "Quantitative analysis of 4 active components in Weishu granules using single marker by QAMS method," Chinese Journal of Pharmaceutical Analysis, vol. 35, pp. 751-757, 2015.

[23] Y. F. Zhang, X. Wang, Y. Bi, Z. Z. Wang, W. Xiao, and P. Li, "Determination of nine components in Reduning Injection by quantitative analysis of multi-components with a singlemarker," Chinese Traditional and Herbal Drugs, vol. 44, pp. 3162-3169, 2013.

[24] B. He, S. Y. Yang, and Y. Zhang, "A new method of calibration and positioning in quantitative analysis of multicomponents by single marker," Acta Pharmaceutica Sinica, vol. 47, no. 12, pp. 1653-1659, 2012.

[25] Y. Q. Wang, G. Y. Wu, H. F. Zhang, L. S. Liu, and J. Zhou, "Determination of 4 triterpenoids contents in bran-fried Alisma orientalis by UPLC and quantitative analysis of multicomponents by single-marker," Journal of Chinese Medicinal Materials, vol. 41, pp. 385-389, 2008.

[26] X. P. Cai, Z. H. Li, J. L. Hua et al., "Determination of six triterpene acid contents in effective fraction of Eriobotryae Folium by quantitative analysis of multi-components by single-marker," Chinese Traditional and Herbal Drugs, vol. 44, pp. 3057-3062, 2013. 